\title{
Frequency-specific corticofugal modulation of the dorsal cochlear nucleus in mice
}

\author{
Lingzhi Kong ${ }^{1 \dagger}$, Colin Xiong ${ }^{1 \dagger}$, Liang $\mathrm{Li}^{2}$ and Jun Yan ${ }^{1 *}$ \\ ' Department of Physiology and Pharmacology, Faculty of Medicine, Hotchkiss Brain Institute, University of Calgary, Calgary, AB, Canada \\ ${ }^{2}$ Department of Psychology, Department of Machine Intelligence, Speech and Hearing Research Center, Key Laboratory on Machine Perception (Ministry of \\ Education), PKU-IDG/McGovern Institute for Brain Research, Peking University, Beijing, China
}

Edited by:

Paul Hinckley Delano, Universidad

de Chile, Chile

\section{Reviewed by:}

Manuel S. Malmierca, University of

Salamanca, Spain

Xavier G. A. Perrot, Université

Claude Bernard Lyon 1, France

\section{*Correspondence:}

Jun Yan, Department of Physiology and Pharmacology, Faculty of

Medicine, Hotchkiss Brain Institute, University of Calgary, 3330 Hospital Drive NW, Calgary, AB T2N 4N1,

Canada

e-mail: juyan@ucalgary.ca

${ }^{\dagger}$ These authors have contributed equally to this work.
The primary auditory cortex (Al) modulates the sound information processing in the lemniscal subcortical nuclei, including the anteroventral cochlear nucleus (AVCN), in a frequency-specific manner. The dorsal cochlear nucleus (DCN) is a non-lemniscal subcortical nucleus but it is tonotopically organized like the AVCN. However, it remains unclear how the Al modulates the sound information processing in the DCN. This study examined the impact of focal electrical stimulation of Al on the auditory responses of the DCN neurons in mice. We found that the electrical stimulation induced significant changes in the best frequency (BF) of DCN neurons. The changes in the BFs were highly specific to the BF differences between the stimulated Al neurons and the recorded DCN neurons. The DCN BFs shifted higher when the AI BFs were higher than the DCN BFs and the DCN BFs shifted lower when the Al BFs were lower than the DCN BFs. The DCN BFs showed no change when the Al and DCN BFs were similar. Moreover, the BF shifts were linearly correlated to the BF differences. Thus, our data suggest that corticofugal modulation of the DCN is also highly specific to frequency information, similar to the corticofugal modulation of the AVCN. The frequency-specificity of corticofugal modulation does not appear limited to the lemniscal ascending pathway.

Keywords: corticofugal modulation, primary auditory cortex, dorsal cochlear nucleus, frequency-specific modulation, lemniscal, non-lemniscal, neural plasticity

\section{INTRODUCTION}

Understanding the central processing of auditory information is incomplete without considering the descending systems. Morphologically, the auditory cortex sends a large number of descending fibers to the subcortical nuclei (corticofugal projections, Doucet et al., 2002, 2003; Coomes and Schofield, 2004), including the auditory thalamus (Roger and Arnault, 1989; Winer et al., 2001), inferior colliculus (Andersen et al., 1980; Faye-Lund, 1985; Coleman and Clerici, 1987; Herbert et al., 1991; Saldaña et al., 1996; Winer et al., 1998, 2002; Bajo and Moore, 2005; Coomes et al., 2005; Bajo et al., 2007; Peterson and Schofield, 2007; Markovitz et al., 2013) and cochlear nucleus (Weedman and Ryugo, 1996a,b; Jacomme et al., 2003; Schofield and Coomes, 2005a,b; Meltzer and Ryugo, 2006; Schofield et al., 2006). In addition, the corticofugal system implements a highly selective modulation of the physiological response in the subcortical nuclei (Yan and Suga, 1996, 1999; Ma and Suga, 2001a; Nakamoto et al., 2008; Bajo et al., 2010). In the frequency domain, focal activation of the primary auditory cortex (AI) shifts the receptive fields of neurons in the subcortical nuclei towards the best frequency $(\mathrm{BF})$ of activated $\mathrm{AI}$ neurons and reorganizes the frequency maps of those subcortical nuclei including the ventral division of the medial geniculate body (MGBv; Zhang and Suga, 2000; Tang et al., 2012), the central nucleus of the inferior colliculus (ICc; Yan and
Suga, 1998; Zhang and Suga, 2000; Yan et al., 2005; Yan and Ehret, 2001, 2002; Ma and Suga, 2001b, 2003) and even the anteroventral cochlear nucleus (AVCN; Luo et al., 2008; Liu et al., 2010).

Frequency-specific corticofugal modulation appears to be a feature of the lemniscal auditory pathway. Up to now, it has been exclusively observed in the lemniscal subcortical nuclei (MGBv, ICc and AVCN) and not in the non-lemniscal nuclei (Calford and Aitkin, 1983; Imig and Morel, 1983; Hu et al., 1994) including those found in the medial division of the medial geniculate body (MGBm) and the external nucleus of the inferior colliculus (ICx; Jen et al., 2001; Zhang and Suga, 2005; Wu and Yan, 2007; Tang et al., 2012). Given that the lemniscal auditory pathway is also characterized by a sharp tuning in sound frequency and a strict tonotopic projection (Calford, 1983; Rodrigues-Dageff et al., 1989; Redies and Brandner, 1991; Anderson and Linden, 2011), the question raised here is whether the frequency-specificity of corticofugal modulation is limited to the lemniscal system or dominated by the tonotopy regime of the central auditory system.

The dorsal cochlear nucleus (DCN) is tonotopically organized (Young et al., 1992; Luo et al., 2009). In contrast to the AVCN, the DCN receives inputs from both the auditory and somatosensory systems (Baizer et al., 2012), and projects to the ICx and MGBm (Malmierca et al., 2002). The DCN could therefore be a nonlemniscal nucleus because it is tightly associated to non-lemniscal 
auditory system (Malmierca et al., 2002; Ryugo et al., 2003; Luo et al., 2012). In the present study, we examined the effects of focal electrical stimulation of the $\mathrm{AI}\left(\mathrm{ES}_{\mathrm{AI}}\right)$ on the auditory responses of the DCN neurons. Our data show that $\mathrm{ES}_{\mathrm{AI}}$ induced a frequencyspecific shift in the frequency tunings of the DCN neurons, similar to the modulation of the AVCN (Luo et al., 2008; Liu et al., 2010).

\section{MATERIALS AND METHODS}

C57 female mice, aged 4-7 weeks and weighing 14.6-20.7 g, were used in this study. All protocols and procedures were approved by the Animal Care Committee of the University of Calgary (protocol number: M04044). Animals were anesthetized with a mixture of ketamine $(85 \mathrm{mg} / \mathrm{kg}$, i.p., Bimeda-MTC Animal Health Inc., Canada) and xylazine (15 mg/kg, i.p., Bimeda-MTC Animal Health Inc.). The anesthetic level was maintained by additional doses of ketamine and xylazine, $17 \mathrm{mg} / \mathrm{kg}$ and $3 \mathrm{mg} / \mathrm{kg}$ respectively. Under anesthesia, the mouse's head was fixed in a custom-made head holder by rigidly clamping between the palate and nasal/frontal bones. The mouth bar was adjusted to align bregma and lambda of the skull in one horizontal plane. Once the mouse's head was positioned, the scalp was incised along the midline and subcutaneous tissue and muscle were removed to expose the skull. Two holes, 3 and $2 \mathrm{~mm}$ in diameter respectively, were drilled to expose the right cerebellum above the cochlear nucleus (5.6-6.5 $\mathrm{mm}$ posterior to bregma, 2.1-2.6 $\mathrm{mm}$ lateral to the midline) and the left AI (2.2-3.6 mm posterior to bregma, 4-4.5 mm lateral to the midline). After surgery, the animal was placed in a sound-proof chamber to record the response of DCN neurons before and after electrical stimulation of the auditory cortex (Figure 1). During all surgery and electrophysiological experiments, the animal's body temperature was maintained at a constant $37^{\circ} \mathrm{C}$ using a feedback-controlled heating pad.

\section{ACOUSTIC STIMULATION}

Tone bursts, 60-ms duration with 5-ms rise and fall times, were used as acoustic stimuli. They were digitally synthesized and converted into analog sinusoidal waves by an Enhanced Realtime Processor (RP2, Tucker-Davis Tech., Gainesville, FL, USA). The signals were then fed to a tweeter via a digital attenuator (PA5, Tucker-Davis Tech., Gainesville, FL, USA). The output amplitude of the tone bursts was expressed as $\mathrm{dB}$ SPL within $1 \mathrm{~dB}$ accuracy (reference $20 \mu \mathrm{Pa}$ ). The tweeter was placed $45^{\circ}$ to the right of and $13 \mathrm{~cm}$ away from the mouse's right ear. During calibration, the tweeter was driven by 20 -volt sinusoidal peak-topeak bursts without attenuation. It was calibrated at the right and left ear of the animal with a condenser microphone (Model 2520, Larson-Davis Laboratories, USA) and a microphone preamplifier (Model 2200C, Larson-Davis Laboratories, USA). Frequencies and intensities of tone bursts were varied either manually or automatically with software (BrainWare, Tucker-Davis Tech., Gainesville, FL, USA).

\section{RECORDING AND ELECTRICAL STIMULATION OF THE AI}

A tungsten electrode $(\sim 2 \mathrm{M} \Omega$ impedance, FHC, USA) was advanced perpendicular to the surface of the left auditory cortex. The electrode was initially connected to the preamplifier of the data acquisition system. Signals from the electrode were fed to

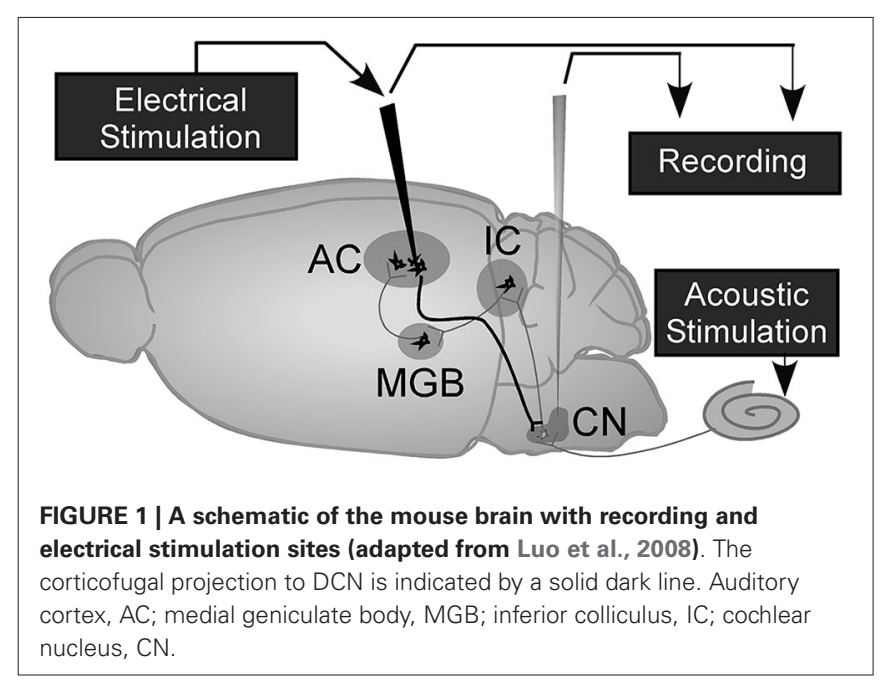

a 16-channel preamplifier, amplified 10,000 times and filtered using a bandwidth of $0.3-10 \mathrm{kHz}$ (RA16, Tucker-Davis Tech., Gainesville, FL, USA), and recorded with software (BrainWare, Tucker-Davis Tech., Gainesville, FL, USA). A pure tone with manual alternation of frequencies and amplitudes was continuously delivered once per second during the electrode penetration. Tone-evoked action potentials were frequently located at layers III/IV of the AI. The lowest amplitude (minimum threshold) and the corresponding frequency at which the neuron showed a response were determined by manual alternation of the tone frequency and amplitude. After $5 \sim 8$ penetrations, a rough tonotopy of the AI and the intended location for stimulation of the AI were determined. Once the electrode was in position and the tone-evoked action potentials were observed again, the frequency tunings of the AI neurons were measured with a series of tone bursts at $10 \mathrm{~dB}$ above the $\mathrm{MT}$ and frequencies that varied from 3 to $40 \mathrm{kHz}$ in $1 \mathrm{kHz}$ steps. Tone stimuli were presented 15 times at each frequency. The frequency to which the neuron showed the largest response magnitude was defined as the BF of the AI neuron. The electrode was then disconnected from the recording system and reconnected to the output of a constant current isolator (A360, WPI Inc., Sarasata, FL) for the $\mathrm{ES}_{\mathrm{AI}}$. The electrode was advanced to a depth of about 700-800 $\mu \mathrm{m}$ below the brain surface to layer $\mathrm{V}$ of the AI where it was maintained for the duration of the experiment. This procedure ensured that the locations of the recording and stimulating sites were in the same AI cell column with the same BFs.

An indifferent electrode was placed on the brain surface just adjacent to the stimulating electrode. The negative pulses (monophasic, $0.1 \mathrm{~ms}, 500 \mathrm{nA}$ constant current) were generated by a stimulator (Grass S88, Natus Neurology, West Warwick, RI) and a constant-current isolator (A360, WPI, Inc., Sarasata, FL, USA). The electrical pulses were synchronized with the offset of the tone bursts at $\mathrm{BF}$ and $20 \mathrm{~dB}$ above the MT of the cortical neurons. The combined acoustic from the tweeter and electric stimuli were respectively delivered in both ears (with a right predominance) and to the left $\mathrm{AI}$ at a rate of $4 \mathrm{~Hz}$ for $7 \mathrm{~min}$; this stimulus paradigm was also used in our previous study (Yan and Ehret, 2002). 


\section{DCN RECORDING}

Two tungsten electrodes ( $\sim 2 \mathrm{M} \Omega$ impedance) were dorsoventrally positioned in the right cochlear nucleus. The space between the two electrodes was $100 \mu \mathrm{m}$. The location of the DCN was determined physiologically. A pure tone with manual alteration of its frequency and amplitude was continuously delivered once per second during electrode penetration. Tone-evoked responses were commonly observed at a depth of $2.5 \mathrm{~mm}$ below the surface of the cerebellum. Once the responses to the tone stimuli were observed, the minimum threshold and the corresponding frequency were measured by manually alternating the frequency and amplitude of the tone. The frequencies at the minimum threshold were measured for each $100-\mu \mathrm{m}$ interval to map, in an approximate manner, the tonotopic organization along the dorsal-ventral axis. According to the three-dimensional tonotopy of the cochlear nucleus obtained from our previous study (Luo et al., 2009), the frequencies at the minimum threshold decreased dorsoventrally in the same frequency range for both the DCN and posteroventral cochlear nucleus (PVCN) neurons. Thus, the ventral boundary of the DCN was determined when the frequency at the minimum threshold increased as the electrode was advanced into the PVCN. The electrode was then withdrawn in $\sim 100$ - $\mu$ m intervals until the action potential recordings stabilized. The minimum threshold and the corresponding frequency of the recorded DCN neuron were determined manually again, and the frequency tunings of the DCN neuron was also measured with the same procedure used for the AI neurons. These response curves of the DCN neurons served as control responses. The frequency to which the neuron showed the largest response magnitude was defined as the BF of the DCN neuron. A negative current of electrical pulses was then delivered to the AI for the micro-electrical stimulation of the AI neurons (4/s for $7 \mathrm{~min}$ ). The response curves of DCN neurons were again recorded immediately after cortical stimulation and every 30 min until a recovery rate of at least $50 \%$ in the $\mathrm{BF}$ was obtained.

\section{DATA PROCESSING}

The tungsten electrode ( $\sim 2 \mathrm{M} \Omega$ impedance $)$ often detected multiunit activities. Cluster cutting isolated and selected single-unit action potentials by examining eight parameters of the action potential waveform, i.e., peak, valley, spike height, spike width, peak time, valley time, and two user-defined voltages (Yan and Ehret, 2002; Yan et al., 2002). Single-unit responses to the series of tones were eventually displayed using post-stimulus timecumulative (PSTC) histograms with a bin width of $1 \mathrm{~ms}$. The BFs of the DCN neurons were compared before (pre-ES BF) and after (post-ES BF) the $\mathrm{ES}_{\mathrm{AI}}$. Since the ranges of upward and downward $\mathrm{BF}$ shifts were found to be similar, the BF shifts were expressed using a linear $\mathrm{kHz}$ scale (Sakai and Suga, 2001; Yan and Ehret, 2002). The changes in the BFs of DCN neurons were analyzed according to the differences in BFs between the recorded DCN neurons and the stimulated cortical neurons.

\section{STATISTICAL ANALYSIS}

Data were expressed as mean $\pm \mathrm{SD}$. The paired $t$-test (twotailed) was used to compare the differences between groups of data. A $p$-value of $<0.05$ was considered to be statistically significant.

\section{RESULTS}

The effects of $\mathrm{ES}_{\mathrm{AI}}$ were studied in 60 contralateral $\mathrm{DCN}$ neurons from 26 mice (2-4 neurons per mouse). The BFs of recorded DCN neurons ranged from 10 to $27 \mathrm{kHz}$ and the BFs of stimulated cortical neurons ranged from 10 to $28 \mathrm{kHz}$. These values fell within the central range of mouse hearing (Zhang et al., 2005). Our data show that the AI significantly impacts the auditory response of the DCN neurons. The changes in the response properties of DCN neurons occurred within $30 \mathrm{~min}$, peaked at $1.5 \mathrm{~h}$, and recovered at $3 \mathrm{~h}$ after the $\mathrm{ES}_{\mathrm{AI}}$.

The $\mathrm{ES}_{\mathrm{AI}}$ clearly changed the frequency tunings of the contralateral DCN neurons. Figure 2 shows three different examples of DCN neurons modulated by $\mathrm{ES}_{\mathrm{AI}}$. In Figure $2 \mathrm{~A}$, the BFs of both cortical and DCN neurons were $11 \mathrm{kHz}$ (matched). The auditory response of the DCN neuron increased after the $\mathrm{ES}_{\mathrm{AI}}$ (facilitation) while the BF of the DCN neuron did not change. Figure $2 \mathbf{B}$ shows that the pre-ES BF of the DCN neuron was 21 $\mathrm{kHz}$ while the cortical neuron had a $\mathrm{BF}$ of $27 \mathrm{kHz}$ (unmatched). The auditory response at the pre-ES BF $(21 \mathrm{kHz}$, control) of the DCN neuron decreased after the $\mathrm{ES}_{\mathrm{AI}}$ (inhibition). Hereafter, we use the "facilitation" and "inhibition" for simplicity. These terms represent the overall increase and decrease in neuronal activity without prejudging their underlying neurobiological mechanisms. However, the auditory response at $24 \mathrm{kHz}$ (post-ES BF of $\mathrm{DCN}$ neuron) showed the largest increase. Both the facilitation and inhibition by $\mathrm{ES}_{\mathrm{AI}}$ resulted in a $\mathrm{BF}$ shift of the DCN neuron from 21 to $24 \mathrm{kHz}$. In Figure 2C, the pre-ES BF $(16 \mathrm{kHz})$ of the $\mathrm{DCN}$ neuron was higher than the $\mathrm{BF}(11 \mathrm{kHz})$ of the cortical neuron (unmatched). The BF of this DCN neuron shifted from 16 to $14 \mathrm{kHz}$ after the $\mathrm{ES}_{\mathrm{AI}}$. Thus, the changes in the BF of the DCN neurons appear to be determined by the relationship between the BFs of the DCN and AI neurons: (1) the DCN BFs did not change when the BFs of the DCN neurons and those of the AI neurons were matched; and (2) the DCN BFs shifted towards the BFs of the $\mathrm{AI}$ neurons when the BFs of the $\mathrm{DCN}$ and $\mathrm{AI}$ neurons were unmatched.

We also analyzed the effect of $\mathrm{ES}_{\mathrm{AI}}$ on the frequency tunings of all 60 DCN neurons. The DCN neurons were classified according to the difference between the BFs of the DCN neurons and AI neurons: (1) unmatched group (14 neurons, $\mathrm{BF}_{\mathrm{DCN}} \approx$ $\mathrm{BF}_{\mathrm{AI}}$, Figure 3, open circles and open bar); (2) unmatched Group 1 (21 neurons, $\mathrm{BF}_{\mathrm{DCN}}-\mathrm{BF}_{\mathrm{AI}}<-1 \mathrm{kHz}$, Figure 3, filled circles and filled bars); and (3) unmatched Group 2 (25 neurons, $\mathrm{BF}_{\mathrm{DCN}}-\mathrm{BF}_{\mathrm{AI}}>1 \mathrm{kHz}$, Figure 3, filled circles and filled bars). For the auditory response (spikes) at the pre-ES BF and $10 \mathrm{~dB}$ above the MT of DCN neurons (control), the response increased after the $\mathrm{ES}_{\mathrm{AI}}$ for the matched group (Figure $3 \mathrm{~A}$, open circles) while it decreased for the unmatched group (Figure 3A, filled black circles). On average, the response of the matched group (Figure 3B, open bar) significantly increased by $9.95 \%$ $(p<0.01)$. In contrast, the response of the unmatched group (Figure 3B, filled black bars) significantly decreased by $6.71 \%$ $(p<0.001)$ for the unmatched Group 1 and $8.36 \%(p<$ $0.001)$ for the unmatched Group 2. For the auditory response (spikes) at the post-ES BF and $10 \mathrm{~dB}$ above the MT of DCN neurons, the response increased after $\mathrm{ES}_{\mathrm{AI}}$ for the unmatched group (Figure 3A, filled gray circles). On average, the response 
of the unmatched group (Figure 3B, filled gray bars) significantly increased by $12.25 \%(p<0.001)$ for the unmatched Group 1 and $10.49 \%(p<0.001)$ for the unmatched Group 2. Thus, the $\mathrm{ES}_{\mathrm{AI}}$ remarkably inhibits the auditory response at the pre-ES BF of DCN neurons while it facilities the auditory response at the post-ES BF when the BFs of the DCN and AI neuron are unmatched.

Our results indicate that the shifts in DCN BFs appear to be associated with the BFs of stimulated cortical neurons. To clarify this issue, we further analyzed the correlation of the shifts in DCN BFs to the BFs of the stimulated AI neurons. It became apparent that the BF changes of DCN neurons were systematically associated with the differences in the BFs between the stimulated $\mathrm{AI}$ neurons and the recorded DCN neurons (Figure 4A). The shift in BFs was linearly correlated with the differences between the BFs of the AI and DCN neurons $\left(R^{2}=0.811 ; p<0.01\right)$. When the BFs of AI neurons were higher than the BFs of DCN neurons, cortical stimulation significantly increased the BFs of DCN neurons by $2.07 \mathrm{kHz}(p<0.001)$, and when BFs of cortical neurons were lower than the BFs of DCN neurons, cortical stimulation significantly decreased the BFs of DCN neurons by $2.77 \mathrm{kHz}(p<0.001)$ (Figure 4B, filled bars). When the BFs of AI neurons were the same as the BFs of DCN neurons (Figure 4A, open circles), cortical stimulation did not shift the BFs of DCN neurons (Figure 4B, open bar).

\section{DISCUSSION}

Our data clearly demonstrated that the auditory cortex modulated the auditory responses of the DCN neurons in a frequency-specific manner. The BF shifts of DCN neurons were significantly correlated to the differences in the BFs between the stimulated AI neurons and the recorded DCN neurons. Thus, the DCN and AVCN not only exhibit mirror-symmetrical tonotopic maps (Luo et al., 2009), but also share a similar pattern of corticofugal modulation (Luo et al., 2008; Liu et al., 2010). Therefore, the frequency-specificity of corticofugal modulation appears to be dominated by the tonotopy regime of the central auditory system. However, the AVCN and DCN belong to two distinct auditory pathways (lemniscal vs. non-lemniscal, respectively) with different anatomical and physiological properties (Calford and Aitkin, 1983; Imig and Morel, 1983; Hu et al., 1994). Given that the corticofugal modulation of AVCN re-shapes the high-fidelity representation of initial sound information and impacts the sound information that progresses upwards through the lemniscal pathway, what is the function of the corticofugal modulation of the DCN in the non-lemniscal pathway?

The non-lemniscal auditory pathway engages in functions complementary with those of the lemniscal auditory pathway including the integration of information within and across sensory modalities, detection of changes in ongoing stimuli and interestingly, tinnitus (Young et al., 1995; Malmierca et al., 2002; Ryugo et al., 2003; Luo et al., 2012). The hyperactivity of the DCN neurons is considered to be a physiological correlate of the somatosensory tinnitus (Kaltenbach and McCaslin, 1996; Zhang and Kaltenbach, 1998; Baizer et al., 2012), and the corticofugal feedbacks, via the frequency-specific enhancement of the tinnitus-related frequencies, could be partially responsible (Mulders and Robertson, 2009; Eggermont, 2012, 2013). Our findings demonstrate that the DCN is modulated by the AI in a frequency-specific manner, suggesting that the AI may contribute

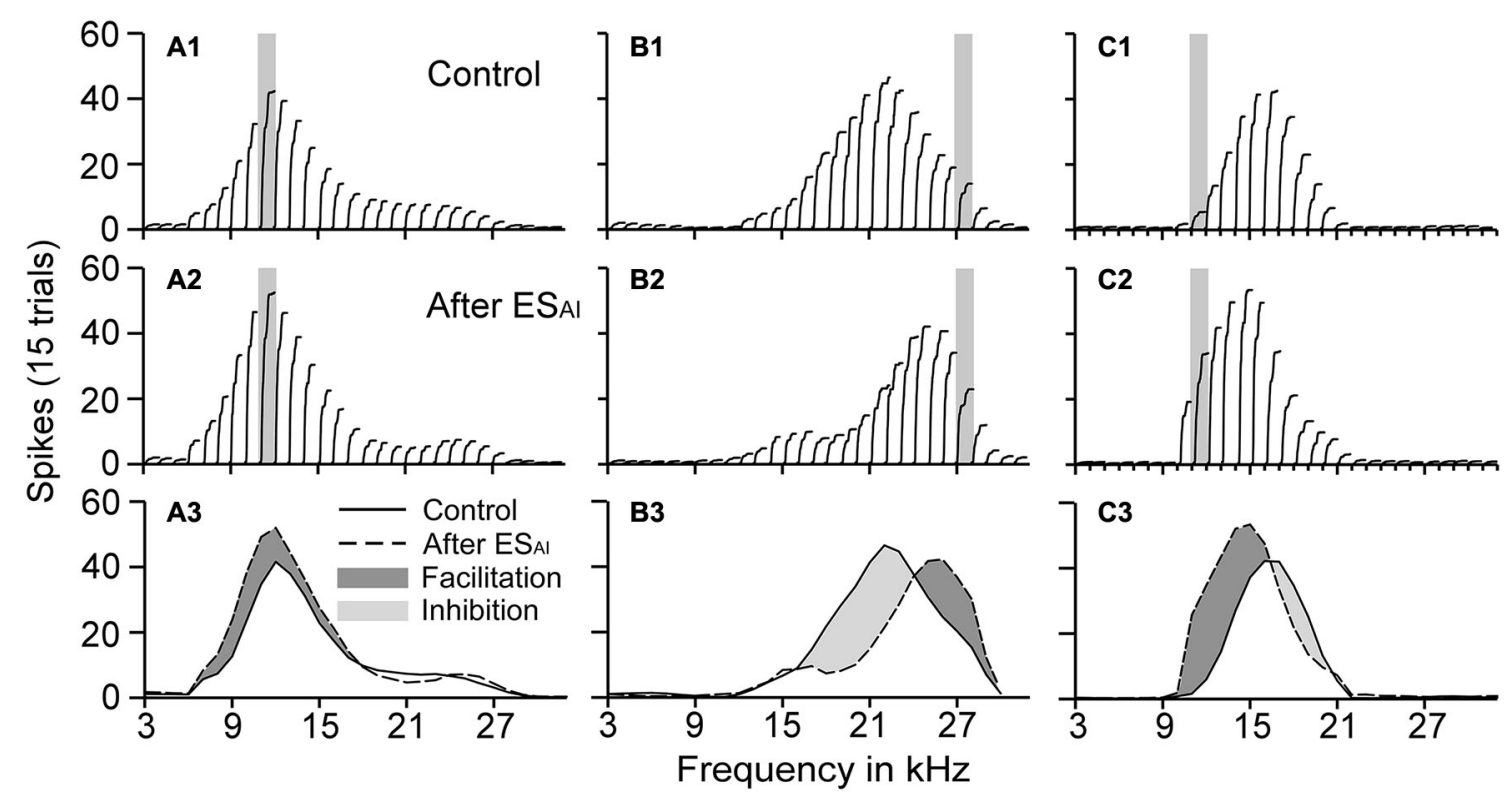

FIGURE 2 | Three examples illustrating the effects of the $\mathrm{ES}_{\mathrm{AI}}$ on the frequency tunings of $\mathbf{D C N}$ neurons $(\mathbf{A}-\mathbf{C})$. The $E S_{A l}$ did not change the BF but increased the auditory responses of the matched DCN neurons ( $A 1, A 2)$, while the BFs of the unmatched DCN neurons shifted towards the cortical BF (B1, B2 and C1, C2). The ES $\mathrm{Al}_{\text {l }}$ caused facilitation (A3, B3, C3) and inhibition (B3, C3) of DCN auditory responses. The gray bars in the top two rows of panels represent the BFs of the stimulated cortical neurons. In the bottom row of panels, the dark gray area represents facilitation, whereas the light gray area represents inhibition. 


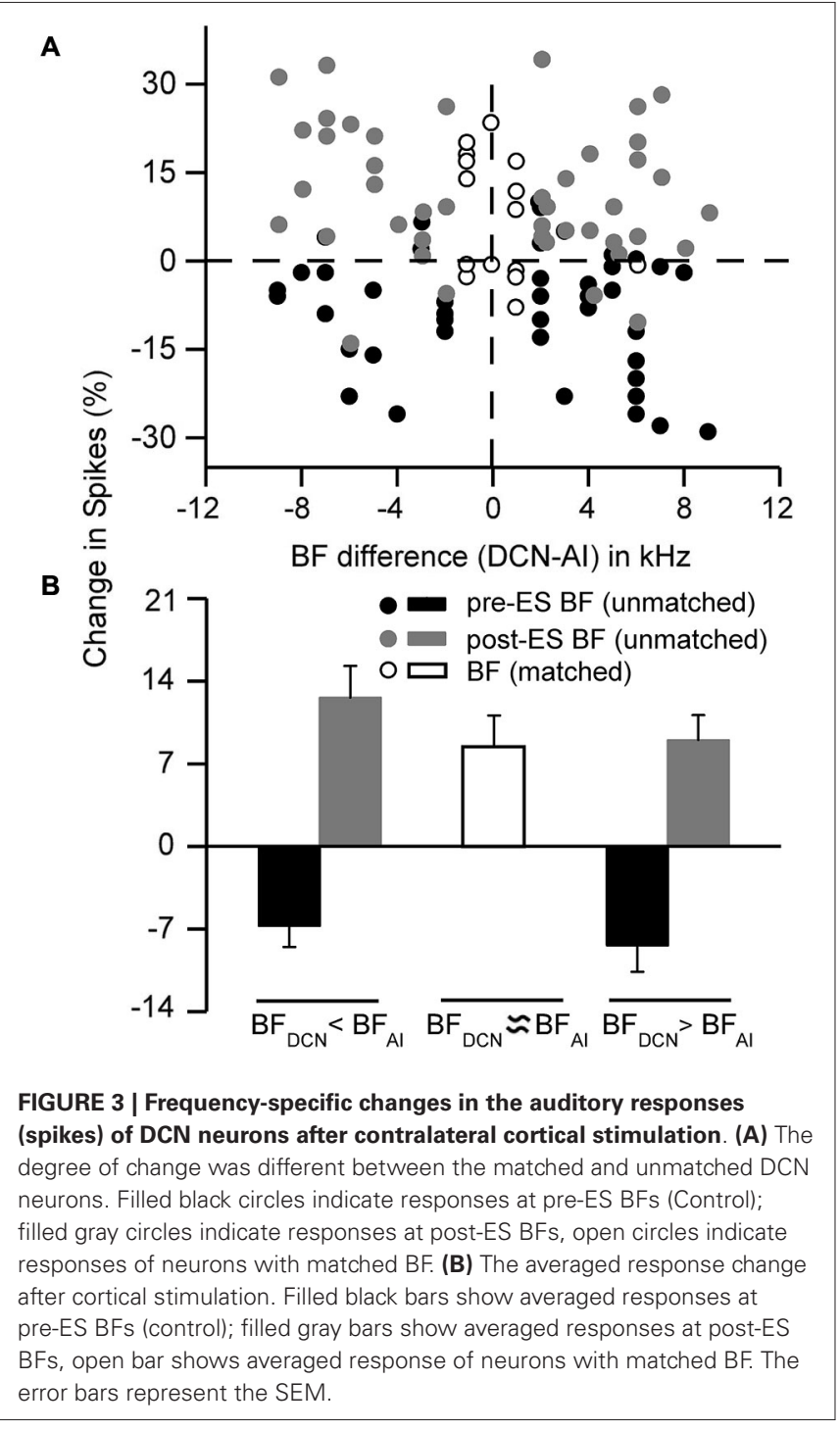

to the chronic form of tinnitus through its modulation of the DCN. The DCN is a relay for auditory information ascending from the periphery to the non-lemniscal pathway. Thus, the AI may also be involved in the other functions of the non-lemniscal pathway.

In addition to tonotopic organization and multisensory inputs, the DCN is a layered structure and consists of distinct cell types including the fusiform cells, giant cells, granule neurons and cartwheel cells (Mugnaini et al., 1980; Browner and Baruch, 1982; Webster and Trune, 1982; Ryugo and Willard, 1985; Willott et al., 1992; Willott, 2001). It has been shown in vitro studies that different types of neurons have different membrane properties and firing patterns (Hirsch and Oertel, 1988; Oertel and $\mathrm{Wu}$, 1989; Zhang and Oertel, 1993a,b,c). It would be interesting to determine how the corticofugal modulation is associated with the layered structure and cell types of DCN.

Considering the multiple descending projections within the auditory system, the auditory cortex may modulate the DCN in a direct or indirect manner. The corticofugal projections to the

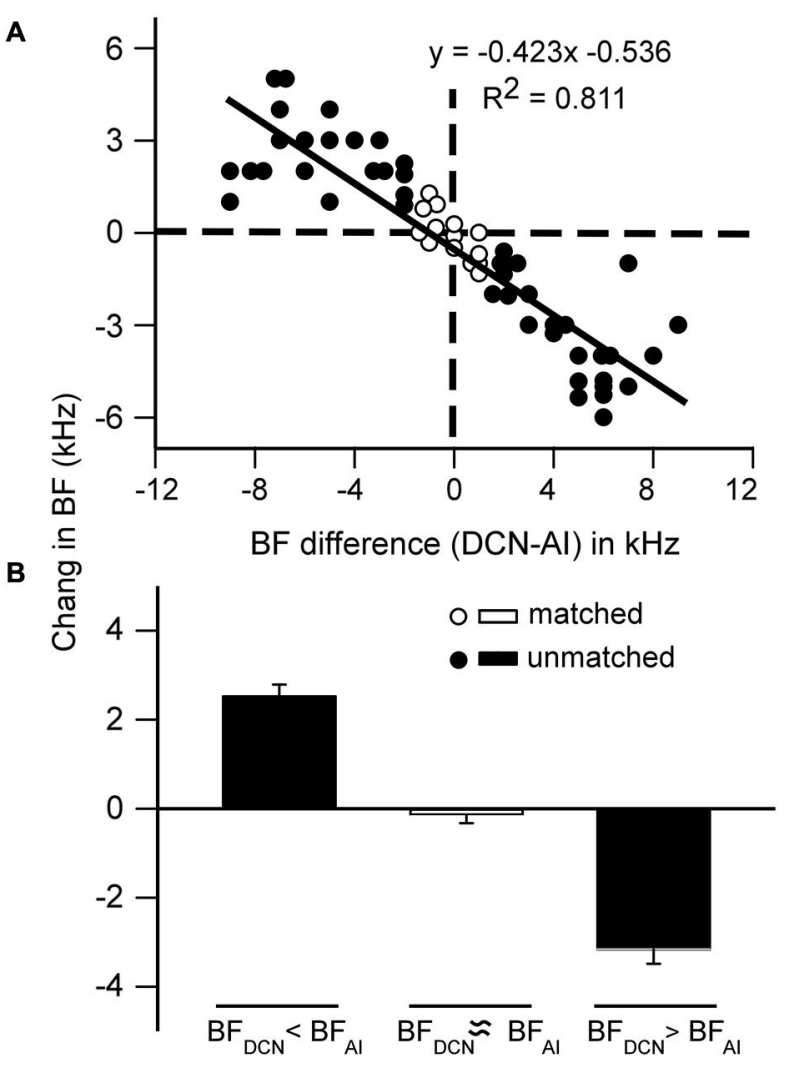

FIGURE 4 | Frequency-specific changes in the BF of DCN neurons after contralateral cortical stimulation. (A) The degree of change was

systematically correlated to the BF difference between the Al and DCN neurons. Open circles, BF shift of neurons with matched BF; filled circles, BF shift of neurons with unmatched BF. (B) The averaged BF change after cortical stimulation. Open bar indicates the BF shift of neurons with matched BF; filled bars indicate the BF shift of neurons with unmatched BF. The error bars represent the SEM.

DCN originate from large pyramidal neurons in layer $\mathrm{V}$ of the $\mathrm{AI}$, and some fibers directly innervate fusiform cells in all layers of the DCN (Jacomme et al., 2003; Meltzer and Ryugo, 2006; Schofield and Coomes, 2005a,b). These fibers allow the cortical neurons to directly impact the activity of the principal DCN neurons. However, the majority of corticofugal fibers terminate in granule cell lamina between the DCN and the PVCN (Weedman and Ryugo, 1996a,b; Doucet et al., 2002, 2003). The corticaldependent modulation of DCN neuronal activity through these fibers may involve intrinsic connections between granule cell lamina and the DCN as well as interconnections between the DCN and the ventral cochlear nucleus (Mugnaini et al., 1980; Snyder and Leake, 1988; Wickesberg and Oertel, 1988; Manis, 1989). Although the number of corticofugal fibers to the DCN is much lower than those to the granule cell lamina, we speculate that the highly specific corticofugal modulation is likely mediated by the corticofugal fibers directly projecting to DCN neurons. This is similar to our observations in the case of corticocollicular modulation. The corticocollicular projections mostly target the caudal cortex, dorsal cortex and lateral nucleus of the inferior colliculus, while the tonotopically-organized ICc only receives 
sparse but tonotopic descending projections from the AI (Saldaña et al., 1996; Winer et al., 1998, 2002; Bajo and Moore, 2005; Bajo et al., 2007). Additionally, direct glutamatergic projections from the AI to the ICc are believed to be responsible for the frequencyspecific corticofugal modulation of the ICc (Yan et al., 2005).

In sum, the AI modulates the neural responses in the DCN in a highly frequency-specific manner, similar to the corticofugal modulation of the AVCN. Thus, the frequency-specificity of corticofugal modulation does not appear limited to the lemniscal ascending pathway but dominated by the tonotopy regime of the auditory system. As the DCN receives many descending projections, their involvement in corticofugal modulation requires careful study.

\section{ACKNOWLEDGMENTS}

This work was supported by grants from the Natural Sciences and Engineering Research Council of Canada (Discovery Grant), the Campbell McLaurin Chair for Hearing Deficiencies, and Alberta Innovates-Health Solutions.

\section{REFERENCES}

Anderson, L. A., and Linden, J. F. (2011). Physiological differences between histologically defined subdivisions in the mouse auditory thalamus. Hear. Res. 274, 48-60. doi: 10.1016/j.heares.2010.12.016

Andersen, R. A., Snyder, R. L., and Merzenich, M. M. (1980). The topographic organization of corticocollicular projections from physiologically identified loci in the AI, AII and anterior auditory cortical fields of the cat. J. Comp. Neurol. 191, 479-494. doi: 10.1002/cne.901910310

Baizer, J. S., Manohar, S., Paolone, N. A., Weinstock, N., and Salvi, R. J. (2012). Understanding Tinnitus: the dorsal cochlear nucleus, organization and plasticity. Brain Res. 1485, 40-53. doi: 10.1016/j.brainres.2012.03.044

Bajo, V. M., and Moore, D. R. (2005). Descending projections from the auditory cortex to the inferior colliculus in the gerbil, Meriones unguiculatus. J. Comp. Neurol. 486, 101-116. doi: 10.1002/cne.20542

Bajo, V. M., Nodal, F. R., Bizley, J. K., Moore, D. R., and King, A. J. (2007). The ferret auditory cortex: descending projections to the inferior colliculus. Cereb. Cortex 17, 475-491. doi: 10.1093/cercor/bhj164

Bajo, V. M., Nodal, F. R., Moore, D. R., and King, A. J. (2010). The descending corticocollicular pathway mediates learning-induced auditory plasticity. Nat. Neurosci. 13, 253-260. doi: 10.1038/nn.2466

Browner, R. H., and Baruch, A. (1982). The cytoarchitecture of the dorsal cochlear nucleus in the 3-month- and 26-month-old C57BL/6 mouse: a Golgi impregnation study. J. Comp. Neurol. 211, 115-138. doi: 10.1002/cne.902110203

Calford, M. B. (1983). The parcellation of the medial geniculate body of the cat defined by the auditory response properties of single units. J. Neurosci. 3, 23502364.

Calford, M. B., and Aitkin, L. M. (1983). Ascending projections to the medial geniculate body of the cat: evidence for multiple, parallel auditory pathways through thalamus. J. Neurosci. 3, 2365-2380.

Coleman, J. R., and Clerici, W. J. (1987). Sources of projections to subdivisions of the inferior colliculus in the rat. J. Comp. Neurol. 262, 215-226. doi: 10.1002/cne. 902620204

Coomes, D. L., and Schofield, B. R. (2004). Projections from the auditory cortex to the superior olivary complex in guinea pigs. Eur. J. Neurosci. 19, 2188-2200. doi: 10.1111/j.0953-816x.2004.03317.x

Coomes, D. L., Schofield, R. M., and Schofield, B. R. (2005). Unilateral and bilateral projections from cortical cells to the inferior colliculus in guinea pigs. Brain Res. 1042, 62-72. doi: 10.1016/j.brainres.2005.02.015

Doucet, J. R., Molavi, D. L., and Ryugo, D. K. (2003). The source of corticocollicular and corticobulbar projections in area Tel of the rat. Exp. Brain Res. 153, 461466. doi: 10.1007/s00221-003-1604-4

Doucet, J. R., Rose, L., and Ryugo, D. K. (2002). The cellular origin of corticofugal projections to the superior olivary complex in the rat. Brain Res. 925, 28-41. doi: 10.1016/s0006-8993(01)03248-6
Eggermont, J. J. (2012). The Neuroscience of Tinnitus. Oxford: Oxford University Press.

Eggermont, J. J. (2013). Hearing loss, hyperacusis, or Tinnitus: what is modeled in animal research? Hear. Res. 295, 140-149. doi: 10.1016/j.heares.2012. 01.005

Faye-Lund, H. (1985). The neocortical projection to the inferior colliculus in the albino rat. Anat. Embryol. (Berl) 173, 53-70. doi: 10.1007/bf00707304

Herbert, H., Aschoff, A., and Ostwald, J. (1991). Topography of projections from the auditory cortex to the inferior colliculus in the rat. J. Comp. Neurol. 304, 103-122. doi: 10.1002/cne.903040108

Hirsch, J. A., and Oertel, D. (1988). Synaptic connections in the dorsal cochlear nucleus of mice, in vitro. J. Physiol. 396, 549-562.

Hu, B., Senatorov, V., and Mooney, D. (1994). Lemniscal and non-lemniscal synaptic transmission in rat auditory thalamus. J. Physiol. 479(Pt. 2), 217-231.

Imig, T. J., and Morel, A. (1983). Organization of the thalamocortical auditory system in the cat. Annu. Rev. Neurosci. 6, 95-120. doi: 10.1146/annurev.ne.06. 030183.000523

Jacomme, A. V., Nodal, F. R., Bajo, V. M., Manunta, Y., Edeline, J. M., Babalian, A., et al. (2003). The projection from auditory cortex to cochlear nucleus in guinea pigs: an in vivo anatomical and in vitro electrophysiological study. Exp. Brain Res. 153, 467-476. doi: 10.1007/s00221-003-1606-2

Jen, P. H., Sun, X., and Chen, Q. C. (2001). An electrophysiological study of neural pathways for corticofugally inhibited neurons in the central nucleus of the inferior colliculus of the big brown bat, Eptesicus fuscus. Exp. Brain Res. 137, 292-302. doi: 10.1007/s002210000637

Kaltenbach, J. A., and McCaslin, D. L. (1996). Increases in spontaneous activity in the dorsal cochlear nucleus following exposure to high intensity sound: a possible neural correlate of Tinnitus. Aud. Neurosci. 3, 57-78.

Liu, X., Yan, Y., Wang, Y., and Yan, J. (2010). Corticofugal modulation of initial neural processing of sound information from the ipsilateral ear in the mouse. PLoS One 5:e14038. doi: 10.1371/journal.pone.0014038

Luo, F., Wang, Q., Farid, N., Liu, X., and Yan, J. (2009). Three-dimensional tonotopic organization of the C57 mouse cochlear nucleus. Hear. Res. 257, 7582. doi: 10.1016/j.heares.2009.08.002

Luo, F., Wang, Q., Kashani, A., and Yan, J. (2008). Corticofugal modulation of initial sound processing in the brain. J. Neurosci. 28, 11615-11621. doi: 10. 1523/JNEUROSCI.3972-08.2008

Luo, H., Zhang, X., Nation, J., Pace, E., Lepczyk, L., and Zhang, J. (2012). Tinnitus suppression by electrical stimulation of the rat dorsal cochlear nucleus. Neurosci. Lett. 522, 16-20. doi: 10.1016/j.neulet.2012.05.072

Ma, X., and Suga, N. (2001a). Corticofugal modulation of duration-tuned neurons in the midbrain auditory nucleus in bats. Proc. Natl. Acad. Sci. US A 98, 14060 14065. doi: 10.1073/pnas.241517098

Ma, X., and Suga, N. (2001b). Plasticity of bat's central auditory system evoked by focal electric stimulation of auditory and/or somatosensory cortices. J. Neurophysiol. 85, 1078-1087.

Ma, X., and Suga, N. (2003). Augmentation of plasticity of the central auditory system by the basal forebrain and/or somatosensory cortex. J. Neurophysiol. 89, 90-103. doi: 10.1152/jn.00968.2001

Malmierca, M. S., Merchán, M. A., Henkel, C. K., and Oliver, D. L. (2002). Direct projections from cochlear nuclear complex to auditory thalamus in the rat. J. Neurosci. 22, 10891-10897.

Manis, P. B. (1989). Responses to parallel fiber stimulation in the guinea pig dorsal cochlear nucleus in vitro. J. Neurophysiol. 61, 149-161.

Markovitz, C. D., Tang, T. T., and Lim, H. H. (2013). Tonotopic and localized pathways from primary auditory cortex to the central nucleus of the inferior colliculus. Front. Neural Circuits 7:77. doi: 10.3389/fncir.2013.00077

Meltzer, N. E., and Ryugo, D. K. (2006). Projections from auditory cortex to cochlear nucleus: a comparative analysis of rat and mouse. Anat. Rec. A Discov. Mol. Cell. Evol. Biol. 288, 397-408. doi: 10.1002/ar.a.20300

Mugnaini, E., Warr, W. B., and Osen, K. K. (1980). Distribution and light microscopic features of granule cells in the cochlear nuclei of cat, rat and mouse. J. Comp. Neurol. 191, 581-606. doi: 10.1002/cne.901910406

Mulders, W. H. A. M., and Robertson, D. (2009). Hyperactivity in the auditory midbrain after acoustic trauma: dependence on cochlear activity. Neuroscience 164, 733-746. doi: 10.1016/j.neuroscience.2009.08.036

Nakamoto, K. T., Jones, S. J., and Palmer, A. R. (2008). Descending projections from auditory cortex modulate sensitivity in the midbrain to cues for spatial position. J. Neurophysiol. 99, 2347-2356. doi: 10.1152/jn.01326.2007 
Oertel, D., and Wu, S. H. (1989). Morphology and physiology of cells in slice preparations of the dorsal cochlear nucleus of mice. J. Comp. Neurol. 283, 228 247. doi: $10.1002 /$ cne. 902830206

Peterson, D. C., and Schofield, B. R. (2007). Projections from auditory cortex contact ascending pathways that originate in the superior olive and inferior colliculus. Hear. Res. 232, 67-77. doi: 10.1016/j.heares.2007.06.009

Redies, H., and Brandner, S. (1991). Functional organisation of the auditory thalamus in the guinea pig. Exp. Brain Res. 86, 384-392. doi: 10.1007/bf00228962

Rodrigues-Dageff, C., Simm, G., de Ribaupierre, Y., Villa, A., de Ribaupierre, F., and Rouiller, E. M. (1989). Functional organisation of the ventral division of the medial geniculate body of the cat: evidence for a rostro-caudal gradient of response properties and cortical projections. Hear. Res. 39, 103-125. doi: 10. 1016/0378-5955(89)90085-3

Roger, M., and Arnault, P. (1989). Anatomical study of the connections of the primary auditory area in the rat. J. Comp. Neurol. 287, 339-356. doi: 10. $1002 /$ cne. 902870306

Ryugo, D. K., Haenggeli, C. A., and Doucet, J. R. (2003). Multimodal inputs to the granule cell domain of the cochlear nucleus. Exp. Brain Res. 153, 477-485. doi: 10.1007/s00221-003-1605-3

Ryugo, D. K., and Willard, F. H. (1985). The dorsal cochlear nucleus of the mouse: a light microscopic analysis of neurons that project to the inferior colliculus. J. Comp. Neurol. 242, 381-396. doi: 10.1002/cne.902420307

Sakai, M., and Suga, N. (2001). Plasticity of the cochleotopic (frequency) map in specialized and nonspecialized auditory cortices. Proc. Natl. Acad. Sci. U S A 98, 3507-3512. doi: 10.1073/pnas.061021698

Saldaña, E., Feliciano, M., and Mugnaini, E. (1996). Distribution of descending projections from primary auditory neocortex to inferior colliculus mimics the topography of intracollicular projections. J. Comp. Neurol. 371, 15-40. doi: 10. 1002/(sici) 1096-9861(19960715)371:1<15::aid-cne2>3.0.co;2-o

Schofield, B. R., and Coomes, D. L. (2005a). Auditory cortical projections to the cochlear nucleus in guinea pigs. Hear. Res. 199, 89-102. doi: 10.1016/j.heares. 2004.08.003

Schofield, B. R., and Coomes, D. L. (2005b). Projections from auditory cortex contact cells in the cochlear nucleus that project to the inferior colliculus. Hear. Res. 206, 3-11. doi: 10.1016/j.heares.2005.03.005

Schofield, B. R., Coomes, D. L., and Schofield, R. M. (2006). Cells in auditory cortex that project to the cochlear nucleus in guinea pigs. J. Assoc. Res. Otolaryngol. 7, 95-109. doi: 10.1007/s10162-005-0025-4

Snyder, R. L., and Leake, P. A. (1988). Intrinsic connections within and between cochlear nucleus subdivisions in cat. J. Comp. Neurol. 278, 209-225. doi: 10. 1002/cne. 902780205

Tang, J., Yang, W., and Suga, N. (2012). Modulation of thalamic auditory neurons by the primary auditory cortex. J. Neurophysiol. 108, 935-942. doi: 10.1152/jn. 00251.2012

Webster, D. B., and Trune, D. R. (1982). Cochlear nuclear complex of mice. Am. J. Anat. 163, 103-130. doi: 10.1002/aja.1001630202

Weedman, D. L., and Ryugo, D. K. (1996a). Projections from auditory cortex to the cochlear nucleus in rats: synapses on granule cell dendrites. J. Comp. Neurol. 371, 311-324. doi: 10.1002/(sici) 1096-9861(19960722)371:2<311::aidcne10>3.0.co;2-v

Weedman, D. L., and Ryugo, D. K. (1996b). Pyramidal cells in primary auditory cortex project to cochlear nucleus in rat. Brain Res. 706, 97-102. doi: 10. 1016/0006-8993(95)01201-x

Wickesberg, R. E., and Oertel, D. (1988). Tonotopic projection from the dorsal to the anteroventral cochlear nucleus of mice. J. Comp. Neurol. 268, 389-399. doi: $10.1002 /$ cne. 902680308

Willott, J. F. (2001). Handbook of Mouse Auditory Research. Boca Raton, FL: CRC Press.

Willott, J. F., Bross, L. S., and McFadden, S. L. (1992). Morphology of the dorsal cochlear nucleus in C57BL/6J and CBA/J mice across the life span. J. Comp. Neurol. 321, 666-678. doi: 10.1002/cne.903210412

Winer, J. A., Chernock, M. L., Larue, D. T., and Cheung, S. W. (2002). Descending projections to the inferior colliculus from the posterior thalamus and the auditory cortex in rat, cat and monkey. Hear. Res. 168, 181-195. doi: 10. 1016/S0378-5955(02)00489-6

Winer, J. A., Diehl, J. J., and Larue, D. T. (2001). Projections of auditory cortex to the medial geniculate body of the cat. J. Comp. Neurol. 430, 27-55. doi: 10 . 1002/1096-9861(20010129)430:1<27::aid-cne1013>3.0.co;2-8
Winer, J. A., Larue, D. T., Diehl, J. J., and Hefti, B. J. (1998). Auditory cortical projections to the cat inferior colliculus. J. Comp. Neurol. 400, 147-174. doi: 10. 1002/(sici) 1096-9861(19981019)400:2<147::aid-cnel>3.3.co;2-v

Wu, Y., and Yan, J. (2007). Modulation of the receptive fields ofmidbrain neurons elicited by thalamic electrical stimulation through corticofugal feedback. $J$. Neurosci. 27, 10651-10658. doi: 10.1523/jneurosci.1320-07.2007

Yan, J., and Ehret, G. (2001). Corticofugal reorganization of the midbrain tonotopic map in mice. Neuroreport 12, 3313-3316. doi: 10.1097/00001756-20011029000033

Yan, J., and Ehret, G. (2002). Corticofugal modulation of midbrain sound processing in the house mouse. Eur. J. Neurosci. 16, 119-128. doi: 10.1046/j.1460-9568. 2002.02046.x

Yan, J., and Suga, N. (1996). Corticofugal modulation of time-domain processing of biosonar information in bats. Science 273, 1100-1103. doi: 10.1126/science. 273.5278.1100

Yan, J., and Suga, N. (1999). Corticofugal amplification of facilitative auditory responses of subcortical combination-sensitive neurons in the mustached bat. J. Neurophysiol. 81, 817-824.

Yan, J., Zhang, Y., and Ehret, G. (2005). Corticofugal shaping of frequency tuning curves in the central nucleus of the inferior colliculus of mice. J. Neurophysiol. 93, 71-83. doi: 10.1152/jn.00348.2004

Yan, J., Zhang, Y., Jia, Z., Taverna, F., McDonald, R., Muller, R., et al. (2002). Place-cell impairment in glutamate receptor 2 mutant mice. J. Neurosci. 22:RC204.

Yan, W., and Suga, N. (1998). Corticofugal modulation of the midbrain frequency map in the bat auditory system. Nat. Neurosci. 1, 54-58. doi: 10.1038/255

Young, E. D., Nelken, I., and Conley, R. A. (1995). Somatosensory effects on neurons in dorsal cochlear nucleus. J. Neurophysiol. 73, 743-765.

Young, E. D., Spirou, G. A., Rice, J. J., and Voigt, H. F. (1992). Neural organization and responses to complex stimuli in the dorsal cochlear nucleus. Philos. Trans. R. Soc. Lond. B Biol. Sci. 336, 407-413. doi: 10.1098/rstb.1992.0076

Zhang, J. S., and Kaltenbach, J. A. (1998). Increases in spontaneous activity in the dorsal cochlear nucleus of the rat following exposure to high-intensity sound. Neurosci. Lett. 250, 197-200. doi: 10.1016/s0304-3940(98)00482-0

Zhang, S., and Oertel, D. (1993a). Cartwheel and superficial stellate cells of the dorsal cochlear nucleus of mice: intracellular recordings in slices. J. Neurophysiol. 69, 1384-1397.

Zhang, S., and Oertel, D. (1993b). Giant cells of the dorsal cochlear nucleus of mice: intracellular recordings in slices. J. Neurophysiol. 69, 1398-1408.

Zhang, S., and Oertel, D. (1993c). Tuberculoventral cells of the dorsal cochlear nucleus of mice: intracellular recordings in slices. J. Neurophysiol. 69, 1409-1421.

Zhang, Y., and Suga, N. (2000). Modulation of responses and frequency tuning of thalamic and collicular neurons by cortical activation in mustached bats. J. Neurophysiol. 84, 325-333.

Zhang, Y., and Suga, N. (2005). Corticofugal feedback for collicular plasticity evoked by electric stimulation of the inferior colliculus. J. Neurophysiol. 94 , 2676-2682. doi: 10.1152/jn.00549.2005

Zhang, Y., Hakes, J. J., Bonfield, S. P., and Yan, J. (2005). Corticofugal feedback for auditory midbrain plasticity elicited by tones and electrical stimulation of basal forebrain in mice. Eur. J. Neurosci. 22, 871-879. doi: 10.1111/j.1460-9568.2005. 04276.x

Conflict of Interest Statement: The authors declare that the research was conducted in the absence of any commercial or financial relationships that could be construed as a potential conflict of interest.

Received: 18 May 2014; accepted: 16 June 2014; published online: 01 July 2014. Citation: Kong L, Xiong C, Li L and Yan J (2014) Frequency-specific corticofugal modulation of the dorsal cochlear nucleus in mice. Front. Syst. Neurosci. 8:125. doi: 10.3389/fnsys.2014.00125

This article was submitted to the journal Frontiers in Systems Neuroscience.

Copyright $\odot 2014$ Kong, Xiong, Li and Yan. This is an open-access article distributed under the terms of the Creative Commons Attribution License (CC BY). The use, distribution or reproduction in other forums is permitted, provided the original author(s) or licensor are credited and that the original publication in this journal is cited, in accordance with accepted academic practice. No use, distribution or reproduction is permitted which does not comply with these terms. 